\title{
Treatment efficacy and re-infection rates of soil-transmitted helminths following mebendazole treatment in schoolchildren, Northwest Ethiopia
}

\author{
Ayalew Jejaw Zeleke ${ }^{1 *}$, Abebe Genetu Bayih ${ }^{1,2}$, Solomon Afework ${ }^{3}$ and John S. Gilleard ${ }^{4}$
}

\begin{abstract}
Background: Transmission of soil-transmitted helminth (STH) infection remains high in Ethiopia. This study aimed at assessing the therapeutic efficacy of mebendazole against soil-transmitted helminths and determining the reinfection rates of the parasites among schoolchildren in Northwest Ethiopia.

Methods: A school-based cross-sectional study was conducted. Data was collected using a structured questionnaire. Stool specimens were examined using direct wet mount microscopy and Kato-Katz methods. Schoolchildren who tested positive for soil-transmitted helminths were treated with $500 \mathrm{mg}$ single-dose of mebendazole. Cure and egg reduction rates were evaluated 2 to 3 weeks post treatment. Moreover, the reinfection rate of these parasites among those who were cured was determined 1 year after treatment. Data were analyzed using SPSS version 20. $P$ value $<0.05$ was considered as statistically significant.

Result: A drug efficacy study was conducted on 62, 52, and 14 children infected by Ascaris lumbricoides (A. lumbricoides), hookworm, and Trichuris trichiura (T. trichiura), respectively. The cure rates (CR) of mebendazole against A. lumbricoides, hookworm, and T. trichiura were found to be $96.9 \%, 23.1 \%$, and, 28.6\%, respectively. The egg reduction rate (ERR) of A. lumbricoides was found to be $99.6 \%$ whereas $49.6 \%$ and $56.3 \%$ were reported for hookworm and T. trichiura, respectively. Eighty schoolchildren who were treated and cured from any STH infections were included for the determination of re-infection rate. Out of 80 children, 36.3\% (29/80) were found to be reinfected after 1 year: 22 (75.9\%), 6 (20.7\%), and 1 (1.3\%) of study participants were re-infected with A. lumbricoides, hookworm, and both infections, respectively. All re-infections were grouped under the "light infection" category.

Conclusion: Mebendazole was found to be highly effective against $A$. lumbricoides, but had relatively low efficacy against hookworms and T. trichiura. These results bring into question the use of mebendazole in STH mass drug administration (MDA) programs in this region if albendazole, a drug with higher efficacy against hookworms, is available. Moreover, a significant number of treated children were re-infected with either or both of $A$. lumbricoides or hookworms 1 year after treatment emphasizing the need for better integrated intestinal helminthiasis control measures.
\end{abstract}

Keywords: Soil-transmitted helminths, Efficacy, Re-infection, Schoolchildren, Mebendazole

\footnotetext{
* Correspondence: ayalewjejaw@gmail.com

'Department of Medical Parasitology, School of Biomedical and Laboratory Sciences, College of Medicine and Health Sciences, University of Gondar,

Gondar, Ethiopia

Full list of author information is available at the end of the article
}

(c) The Author(s). 2020 Open Access This article is licensed under a Creative Commons Attribution 4.0 International License, which permits use, sharing, adaptation, distribution and reproduction in any medium or format, as long as you give appropriate credit to the original author(s) and the source, provide a link to the Creative Commons licence, and indicate if changes were made. The images or other third party material in this article are included in the article's Creative Commons licence, unless indicated otherwise in a credit line to the material. If material is not included in the article's Creative Commons licence and your intended use is not permitted by statutory regulation or exceeds the permitted use, you will need to obtain permission directly from the copyright holder. To view a copy of this licence, visit http://creativecommons.org/licenses/by/4.0/. 


\section{Background}

Soil-transmitted helminths are among the most widespread infectious agents in tropical and sub-tropical regions of the developing world. They are principally associated with inadequate sanitation, poverty, and poor water sources [1, 2]. Human intestinal helminthiasis is most commonly caused by soil-transmitted helminths (STHs), namely Ascaris lumbricoides, Trichuris trichiura, and hookworms (Necator americanus and Ancylostoma duodenale) [3].

Schoolchildren are high-risk groups for intestinal helminth infections. This has a significant adverse effect on survival, cognitive, and physical development of the children [4, 5]. Moreover, they are associated with poor school performance and absenteeism [6]. Although all STHs are associated with anemia, hookworm has a more pronounced effect on the child's nutrition. It can also cause chronic intestinal blood loss which can result in iron deficiency anemia [5].

In Ethiopia, the current strategy to control STH infections is preventive chemotherapy, which involves a repeated large-scale administration of antihelmintic drugs to at-risk populations, most importantly to preschool and school-aged children. These mass drug administration (MDA) programs have been implemented to decrease the prevalence, intensity, and morbidity associated with STH infections. The MDA programs are implemented based on a periodic distribution of a single dose of a benzimidazole (BZ) drug (albendazole or mebendazole) [7]. Even though the anti-helmintic drugs are available and widely used, their efficacy varies and the drugs do not prevent re-infection. Moreover, low anthelminthic drug efficacy has been reported in helminth infections such as T. trichiura and hookworm. Similarly, other studies have highlighted the low cure rate (CR), e.g., $79.6 \%$ for hookworm and $63.1 \%$ for $T$. trichiura against mebendazole. In general, a number of studies have shown that the therapeutic efficacy of benzimidazole drugs against soil-transmitted helminths is decreased [8] (Ref).

The WHO (World Health Organization) recommends assessing the treatment efficacy, re-infection rates, and the effectiveness of MDA campaigns. This information is important for policy makers of a country about the value of MDA as a tool to eliminate morbidity caused by STHs [9]. Thus, this study aimed to assess the therapeutic efficacy of mebendazole against soil-transmitted helminths and determine the re-infection rates of the parasites among school children in Northwest Ethiopia.

\section{Materials and methods}

\section{Study design and period}

A school-based follow-up cross-sectional study was conducted. Study participants were recruited from Sanja $\left(13^{\circ} 20^{\prime} \mathrm{N} / 36^{\circ} 45^{\prime} \mathrm{E}\right)$, Maksegnit $\left(12^{\circ} 40^{\prime} \mathrm{N} / 37^{\circ} 20^{\prime} \mathrm{E}\right.$, Debark ( $\left.13^{\circ} 08^{\prime} \mathrm{N} / 37^{\circ} 54^{\prime} \mathrm{E}\right)$, Chuahit $\left(12^{\circ} 40^{\prime} \mathrm{N} / 37^{\circ}\right.$ $10^{\prime}$ E) Northwest Ethiopia. Base line data was collected from January 21 to February 21, 2018, while post treatment data was collected from February 4 to March 4, 2018. Moreover, the data for re-infection rate assessment was collected after a year within January 21 to 25, 2019.

\section{Sample size and sampling technique}

The sample size was calculated based on WHO guidelines to assess the efficacy of antihelmintic drugs [10]. According to the guideline, a sample of 50 children positive for each of the parasites targeted by the investigators is sufficient to evaluate the efficacy of a drug. The number to be screened was estimated according to the prevalence in the study area and with the compliance rate of $80 \%$. The prevalence of hookworm infection $(P=37.1 \%)$ was taken from a previous study conducted at Sanja town, northwest Ethiopia [11]. Therefore, the number of schoolchildren to be screened was calculated using the formula of number of expected study participants divided by compliance and prevalence rate of any of the $\mathrm{STH}$ infection. The final sample size was calculated to be a minimum of 504 schoolchildren. The sample size was equally divided amongst each site, i.e., 126 study participants from each study site. Schools and study participants were selected purposefully. Thus, a convenient sampling technique was used to recruit study participants in the study.

All children positive for any of the three soiltransmitted helminths (single infection), with a signed informed consent, and who did not have any additional health problems (based on medical history, physical examination, and vital signs) were included in the study. On the other hand, children who received any form of antihelmintic treatment within the past 30 days, had diarrhea, had experienced a severe allergic reaction to mebendazole, or were infected with other parasitic infections were excluded from the study.

\section{Baseline parasitological survey}

Trained data collectors were recruited, and the data collection process was supervised by the investigators. At each data collection location, sufficient explanation about the aim of the research was given to the students, schoolteachers, and parents before the interview. Stool specimens were then collected from each schoolchild using a clean 10-g volume of stool sample container and labeled with unique identification number. The children were instructed on how to provide a stool specimen of their own, avoiding contamination with urine. Each stool sample was transported to the University of Gondar Laboratory within $2 \mathrm{~h}$ of collection. Each stool specimen was examined using wet mount microscopy and a Kato- 
Katz slide with $41.7 \mathrm{mg}$ template size. The Kato-Katz slides were examined within 30-60 min of preparation for STH eggs. Then, infection intensity of all STHs was calculated by multiplying the average number of eggs counted in Kato-Katz slides by 24, which gives as the eggs per gram (epg) of stool. Results of the laboratory investigation were recorded on reporting sheets prepared for reporting of results. The infection intensities were classified as light, moderate, and heavy per the threshold set by WHO [12].

\section{Drug administration}

Each child was given a light snack (e.g., a slice of bread or a biscuit) before the drug was administered. Then, each child was given a single dose of mebendazole $\left(V{ }^{\circ}{ }^{\circ}\right)$ which was provided by the local coordinator office for the de-worming program. The expiry date and the storage condition of the drug were checked prior to administration. The tablet was administered by trained nurses, and each child was kept under direct observation for approximately $4 \mathrm{~h}$. The children remained at school and continued their usual activities, but they were asked to report any side-effect to a member of the investigation team as soon as possible.

\section{Follow-up survey}

Children who had a specimen positive for any STH infection and treated by mebendazole at baseline were requested to provide a second specimen within 14 to 21 days ( 2 to 3 weeks) from the treatment period. Schools were followed-up in the same order as in the baseline survey. Children who were absent at school on the follow-up day or did not bring a specimen were traced 1 or 2 days later. The laboratory methods used in the baseline survey were also applied in the follow-up survey [10].

\section{Re-infection rate assessment}

Children who were positive for any STH infection during the baseline survey and negative following 14 to 21 days of post treatment were re-tested 12 months after the post-treatment period. The same laboratory techniques were utilized as in the baseline and posttreatment analysis.

\section{Quality assurance mechanisms}

To avoid observer bias, two experienced microscopists performed the laboratory work. Independent readings of slides by the laboratory personnel were checked by another expert. The results of their observation were recorded for later comparison on separate sheets. A quality control was done by repeating all discordant results.

\section{Data management and analysis}

Data was checked for completeness and then entered, edited, and cleaned using SPSS version 20 software. The overall mebendazole efficacy was determined and recorded using a descriptive method of data analysis. The following formula was used to calculate the cure rate (CR) and egg reduction rate (ERR) as it is described before [10].

$$
\begin{aligned}
& \mathrm{CR}=\frac{\text { Number of negative children after treatment who were positive at baseline }}{\text { numberofpositivechildrenbeforetreatment }} \times 100 \\
& \mathrm{ERR}=\left(1-\frac{\text { Arithmetic mean egg counts at follow }- \text { up }}{\text { Arithmetic mean egg counts at baseline }}\right) \times 100
\end{aligned}
$$

\section{Results}

\section{Parasitological cure and egg reduction rates}

A total of 130 schoolchildren who were infected with any STH species were treated with a 500-mg single dose of mebendazole. The number of schoolchildren who were infected with A. lumbricoides, hookworm, and $T$. trichiura were 64,52 , and 14 , respectively. The cure rates of the drug against these parasites are shown in Table 1.

The ERR and mean egg intensities during pre-and post-treatment periods of the three soil-transmitted helminths are presented in Table 2. Moreover, their infection intensity category, both before and after treatment, is stated in the same table.

\section{Re-infection rate of STH infections}

Eighty schoolchildren who were treated and cured of any of the STH infections from 14 to 21 days posttreatment were included for the determination of the reinfection rate after 1 year. Accordingly, the STH reinfection rate was found to be $36.3 \%$ (29/80), and all were light infections. A .lumbricoides was the most frequently isolated parasite in the re-infection assessment study (Table 3).

Potential associations of the outcome variable with some common socio-demographic variables were examined. However, the re-infection rate did not show any significant association with age or sex (Table 4).

\section{Discussion}

Soil-transmitted helminths remain one of the most important public health problems in Ethiopia [13-15]. In the current study, the therapeutic efficacy of mebendazole against three soil-transmitted helminths has been evaluated among schoolchildren. Moreover, the children's re-infection rate has been determined. According to this study, a 500-mg single dose of mebendazole had a satisfactory effect on A. lumbricoides. In other words, the CR against the parasite was found to be $96.9 \%$. This is in line with studies conducted elsewhere in the world 
Table 1 Cure rates (CR) and 95\% of Cl of CR of mebendazole against STHs among schoolchildren in Northwest Ethiopia, 2018

\begin{tabular}{lll}
\hline Type of STHs & $\begin{array}{l}\text { Cured, } \boldsymbol{n}(\%), \\
\mathbf{9 5 \%} \mathbf{C l}\end{array}$ & $\begin{array}{l}\text { Uncured, } \boldsymbol{n} \text { (\%), } \\
\mathbf{9 5 \%} \mathrm{Cl}\end{array}$ \\
\hline A. lumbricoides, $n=64$ & $62(96.9), 92.6-101$ & $2(3.1),-1-7$ \\
Hookworm, $n=52$ & $12(23.1), 11.6-34.5$ & $40(76.9), 65-88$ \\
T. trichiura, $n=14$ & $4(28.6), 4.9-52$ & $10(71.4), 47.7-95$ \\
\hline
\end{tabular}

$n$ number of infected schoolchildren by each soil-transmitted helminths (STH), $\mathrm{Cl}$ confidence interval

where soil-transmitted helminths are endemic (97.6\%) [8], Western Indonesia (100\%) [16], and Tanzania (95\%) [17]. The second therapeutic efficacy indicator of antihelminthic drugs is egg reduction rate (ERR). Hence, the ERR of the same drug for $A$.lumbricoides treatment in this study was $99.9 \%$. This is similar with the previous studies in other regions $[8,16,17]$. This study suggests that single dose of mebendazole is still highly effective for the treatment of ascariasis in Northwest Ethiopia.

Although the current study showed that mebendazole was very effective for ascariasis treatment, its cure rate for hookworms was only $23.1 \%$ and the ERR was only $49.6 \%$. Similar findings have been reported from many different regions of the world e.g., cure rates in Tanzania (25\%) [17], Southern Lao PDR (17.6\%) [18] and Vietnam (38\%) [19]. A review of 29 different efficacy studies found a mean cure rate of
25.5\% (range 2.9-91.1\%) for mebendazole against hookworms (Mrus 2018). Similarly, a meta-analysis of randomized controlled trials across many different countries (55 trials for cure rates and 46 trials for egg reduction rates) showed mebendazole to have much lower efficacy against hookworms than did albendazole: overall cure rates were $32.5 \%$ (95\% confidence interval 20.8 to $46.9 \%$ ) and $79.5 \%$ (95\% confidence interval 71.5 to $85.6 \%$ ) and overall egg reduction rates were $61.0 \%$ (95\% confidence interval 52.0 to $69.9 \%$ ) and $89.6 \%$ (95\%, 81.9 to $97.3 \%)$ for mebendazole and albendazole, respectively [18, 19] (Ref). This study further indicates that a single dose of mebendazole is not very effective for hookworm treatment in Northern Ethiopia and that its use as part of MDA programs in the region should be re-evaluated.

As far as the efficacy of mebendazole against $T$. trichuira is concerned, its cure rate was unsatisfactory being only $28.6 \%$. The ERR was also found to be low (56.3\%). This finding is similar to studies conducted in Tanzania (value) [17] and Southern Lao PDR (17.6\%) [18]. Hence, this study indicates that mebendazole has low efficacy against both hookworm and T. trichuira. As with other studies, it is unclear whether this reflects some degree of anthelmintic drug resistance and further work will be required to investigate the reason behind this observation.

Table 2 STH infection intensity and egg reduction rates in pre- and post-treatment periods among schoolchildren in Northwest Ethiopia, 2018

\begin{tabular}{llll}
\hline Parasite species & Pretreatment, $\boldsymbol{n}(\%)$ & Post treatment, $\boldsymbol{n}$ (\%) & \\
\hline $\begin{array}{l}\text { A. lumbricoides, } n=64 \\
\text { Infection intensity }\end{array}$ & & $2(100)$ & 99.9 \\
Light & $46(71.9)$ & $0(0)$ \\
Moderate & $17(26.6)$ & $0(0)$ \\
Heavy & $1(1.6)$ & 2.8 \\
Mean epg & 5186.4 & \\
Hookworm, $n=52$ & & $40(100)$ \\
Infection intensity & & $0(0)$ \\
Light & $52(100)$ & $0(0)$ \\
Moderate & $0(0)$ & 168.5 \\
Heavy & $0(0)$ & \\
Mean epg & 334.4 & $10(100)$ \\
T. trichiura, $n=14$ & & $0(0)$ \\
Infection intensity & $14(100)$ & $0(0)$ \\
Light & $0(0)$ & 65.1 \\
Moderate & $0(0)$ & 49.6 \\
Heavy & 149 & 56.3 \\
Mean epg & &
\end{tabular}

$n$ number of infected schoolchildren by each soil-transmitted helminths (STH) 
Table 3 Intensity of STH infection among re-infected schoolchildren in Northwest Ethiopia, $n=80$

\begin{tabular}{llllll}
\hline & Re-infected, $\boldsymbol{n}$ (\%) & Light & Moderate & Heavy & Mean epg \\
\hline $\mathrm{Al}, n=22$ & $22(75.9 \%)$ & $22(100 \%)$ & $0(0 \%)$ & $0(0 \%)$ & $0(0 \%)$ \\
$\mathrm{HW}, n=6$ & $6(20.7 \%)$ & $7(100 \%)$ & $0(0 \%)$ & - & - \\
$\mathrm{AL}+\mathrm{HW}, n=1$ & $1(3.4 \%)$ & $1(100)$ & - & - & - \\
Overall & $29(36.3)$ & - & - & - \\
\hline
\end{tabular}

Al A. lumbricoides, Hw Hookworm

The current study has also assessed the re-infection status of the schoolchildren due to soil-transmitted helminthiasis after a year of cure time. Accordingly, a re-infection rate of $36.3 \%(95 \% \mathrm{CI}, 30-53 \%)$ was observed. Similar re-infection findings were reported from Chencha District, southern Ethiopia (36.8\%) [20]. The re-infection rate was mainly due to $A$. lumbricoides $(75.9 \%)$ followed by hookworm (20.9\%). The higher re-infection rate by $A$. lumbricoides than the other two STH infections might be related with its ubiquitous nature and large levels of environmental contamination due to the extreme resistance of its egg to harsh environments. The incidence of a significant number of re-infections by STHs in the region may partly indicate that the existing prevention and control strategies are not adequate enough for the achievement of elimination goals of soil-transmitted helminthiasis related morbidity in the country by 2020 [21].

Finally, the present study revealed that STH reinfection rate among schoolchildren did not show any statistically significant association with sex or age. This implies that the probability of exposure for all schoolchildren in the study area was comparable. Thus, further comprehensive studies which include the description of several possible factors leading to frequent infections of schoolchildren by STHs are necessary in the area.

The limitation of this study is that only a single stool specimen had been used for parasite investigation which might have affected the detection rate of the parasite

Table 4 Association of sex and age with re-infection rates of STH among schoolchildren in Northwest Ethiopia $(n=80)$

\begin{tabular}{clll}
\hline Variables & \multicolumn{2}{l}{ Re-infection status } & $\begin{array}{l}\boldsymbol{P} \\
\text { value }\end{array}$ \\
\cline { 2 - 3 } Sex & Re-infected, $\boldsymbol{n}(\%)$ & Not re-infected, $\boldsymbol{n}(\%)$ & .364 \\
Female & $19(38.8 \%)$ & $30(61.2 \%)$ & \\
Male & $10(32.3 \%)$ & $21(67.7 \%)$ & \\
Total & $29(36.3 \%)$ & $41(63.7 \%)$ & .558 \\
Age in years & & & \\
$7-12$ & $22(36.7 \%)$ & $38(63.3 \%)$ & \\
$>12$ & $7(35 \%)$ & $13(65 \%)$ & \\
Total & $29(36.3 \%)$ & $41(63.7 \%)$ & \\
\hline
\end{tabular}

due to intermittent egg excretion rates by the adult parasites. Moreover, only 14 study participants were involved for T. trichiura drug efficacy study and this might have also affected the interpretation of mebendazole efficacy against $T$. trichiura.

\section{Conclusion}

Mebendazole was found to be highly effective against $A$. lumbricoides. However, its therapeutic efficacy was low against both hookworm and T. trichiura. This questions its use in MDA programs if albendazole, a more efficacious drug against hookworms, is available. Moreover, a considerable number of re-infection rates within a year of the post-treatment period may indicate that the elimination and control of soil-transmitted helminths is challenged by several factors. Thus, the implementation of more evidence-based and integrated preventive strategies is an important goal.

\section{Acknowledgements}

We would like to thanks the Bill and Melinda Gates Foundation (grant number OPP1172974) and the University of Calgary for financial support for this research. We are grateful to all study participants, parents,

schoolteachers, and data collectors.

\section{Authors' contributions}

AJZ involved in the data collection and analysis and drafted the manuscript. AGB involved in the data collection and analysis. JG critically reviewed the manuscript. All authors conceived and planned the study and reviewed and approved the manuscript.

\section{Funding}

The research was funded by the University of Calgary, Canada.

\section{Availability of data and materials}

All data generated or analyzed during this study are included in this published article.

\section{Ethics approval and consent to participate}

Ethical approval was obtained for this study from the research and ethical review committee of the University of Gondar (ethics certification ON/P/ RCS/05/Ho61/2017) and the Conjoint Health Research Ethics Board (CHREB) of the University of Calgary (ethics certification REB17-0719). The objective of the study was fully explained to the local (district) administration and the school principals. Then, the study was started only after a written permission was obtained from the aforementioned institutions. Moreover, an assent was obtained for children older than 12 years. Data collected from every study participant was coded and kept confidential.

\section{Consent for publication}

Not applicable in this section

Competing interests

The authors declare that they have no competing interests. 


\section{Author details}

'Department of Medical Parasitology, School of Biomedical and Laboratory Sciences, College of Medicine and Health Sciences, University of Gondar, Gondar, Ethiopia. ${ }^{2}$ Armauer Hansen Research Institute, Addis Ababa, Ethiopia. ${ }^{3}$ Department of Internal Medicine, University of Gondar, Gondar, Ethiopia. ${ }^{4}$ Department of Comparative Biology and Experimental Medicine, Faculty of Veterinary Medicine, Host-Parasite Interactions Program, University of Calgary, Calgary, Canada.

Received: 27 July 2020 Accepted: 2 November 2020

Published online: 12 November 2020

\section{References}

1. Steventon A, Bardsley M, Billings J, Dixon J, Doll H, Hirani S, et al. Effect of telehealth on use of secondary care and mortality: findings from the Whole System Demonstrator cluster randomised trial. Bmj. 2012;344. https://doi. org/10.1136/bmj.e3874

2. Hotez PJ, Alvarado M, Basáñez M-G, Bolliger I, Bourne R, Boussinesq M, et al The global burden of disease study 2010: interpretation and implications for the neglected tropical diseases. PLoS Negl Trop Dis. 2014;8(7):e2865.

3. Naing C, Whittaker MA, Nyunt-Wai V, Reid SA, Wong SF, Mak JW, et al. Malaria and soil-transmitted intestinal helminth co-infection and its effect on anemia: a meta-analysis. Trans. R. Soc. Trop. Med. Hyg. 2013; 107(11):672-83

4. Albonico M, Allen H, Chitsulo L, Engels D, Gabrielli A-F, Savioli L. Controlling soil-transmitted helminthiasis in pre-school-age children through preventive chemotherapy. PLoS Negl Trop Dis. 2008;2:3.

5. Jamison D, Breman J, Measham A, Alleyne G, Claeson M, Evans D, et al. Helminth infections: soil-transmitted helminth infections and schistosomiasis--disease control priorities in developing countries. 2006.

6. Pabalan N, Singian E, Tabangay L, Jarjanazi H, Boivin MJ, Ezeamama AE. Soiltransmitted helminth infection, loss of education and cognitive impairment in school-aged children: a systematic review and meta-analysis. PLoS Negl Trop Dis. 2018;12:1

7. WHO. First WHO report on neglected tropical diseases: working to overcome the global impact of neglected tropical diseases. First WHO report on neglected tropical diseases: Working to overcome the global impact of neglected tropical diseases. https://www.who.int/neglected_ diseases/2010report/en/. Accessed 31 Oct 2020.

8. Levecke B, Montresor A, Albonico M, Ame SM, Behnke JM, Bethony JM, et al. Assessment of anthelmintic efficacy of mebendazole in schoolchildren in six countries where soil-transmitted helminths are endemic. PLoS Negl Trop Dis. 2014;8(10):e3204.

9. $\mathrm{WHO}$. WHO expert committee on specifications for pharmaceutical preparations: fiftieth report: https://www.who.int/medicines/publications/ pharmprep/trs_996/en/. Accessed 31 Oct 2020.

10. WHO. Assessing the efficacy of anthelminthic drugs against schistosomiasis and soil-transmitted helminthiases; https://apps.who.int/iris/handle/10665/ 79019. Accessed 31 Oct 2020

11. Worku L, Damte D, Endris M, Tesfa H, Aemero M. Schistosoma mansoni infection and associated determinant factors among school children in Sanja Town, Northwest Ethiopia. J Parasitol Res. 2014;2014.

12. Montresor A, Crompton DW, Hall A, Bundy D, Savioli L. Guidelines for the evaluation of soil-transmitted helminthiasis and schistosomiasis at community level: a guide for managers of control programmes. Geneva: World Health Organization. https://apps.who.int/iris/handle/10665/63821. Accessed 31 Oct 2020

13. Molla E, Mamo H. Soil-transmitted helminth infections, anemia and undernutrition among schoolchildren in Yirgacheffee, South Ethiopia. BMC Res. Notes. 2018;11(1):585.

14. Nute AW, Endeshaw $T$, Stewart AE, Sata E, Bayissasse B, Zerihun M, et al. Prevalence of soil-transmitted helminths and Schistosoma mansoni among a population-based sample of school-age children in Amhara region, Ethiopia. Parasites Vectors. 2018;11(1):431.

15. Mengist HM, Zewdie O, Belew A. Intestinal helminthic infection and anemia among pregnant women attending ante-natal care (ANC) in East Wollega, Oromia, Ethiopia. BMC Res. Notes. 2017;10(1):440.

16. Lubis IND, Pasaribu S, Lubis CP. Current status of the efficacy and effectiveness of albendazole and mebendazole for the treatment of Ascaris lumbricoides in North-Western Indonesia. Asian Pacific J. 2012;5(8):605-9.
17. Speich B, Moser W, Ali SM, Ame SM, Albonico M, Hattendorf J, et al. Efficacy and reinfection with soil-transmitted helminths 18-weeks post-treatment with albendazole-ivermectin, albendazole-mebendazole, albendazoleoxantel pamoate and mebendazole. Parasites Vectors. 2016;9(1):123.

18. Soukhathammavong PA, Sayasone S, Phongluxa K, Xayaseng V, Utzinger J, Vounatsou $P$, et al. Low efficacy of single-dose albendazole and mebendazole against hookworm and effect on concomitant helminth infection in Lao PDR. PLoS Negl Trop Dis. 2012;6(1):e1417.

19. Flohr C, Tuyen LN, Lewis S, Minh TT, Campbell J, Britton J, et al. Low efficacy of mebendazole against hookworm in Vietnam: two randomized controlled trials. Am. J. Trop. Med. Hyg. 2007;76(4):732-6.

20. Zerdo Z, Yohanes T, Tariku B. Soil-transmitted helminth reinfection and associated risk factors among school-age children in Chencha District, southern Ethiopia: a cross-sectional study. J Parasitol Res. 2016;2016.

21. Mengitsu B, Shafi O, Kebede B, Kebede F, Worku DT, Herero M, et al. Ethiopia and its steps to mobilize resources to achieve 2020 elimination and control goals for neglected tropical diseases: spider webs joined can tie a lion. Int Health. 2016;8(suppl_1):i34-52.

\section{Publisher's Note}

Springer Nature remains neutral with regard to jurisdictional claims in published maps and institutional affiliations.
Ready to submit your research? Choose BMC and benefit from:

- fast, convenient online submission

- thorough peer review by experienced researchers in your field

- rapid publication on acceptance

- support for research data, including large and complex data types

- gold Open Access which fosters wider collaboration and increased citations

- maximum visibility for your research: over $100 \mathrm{M}$ website views per year

At $\mathrm{BMC}$, research is always in progress.

Learn more biomedcentral.com/submissions 